\title{
BMJ Open Cross-sectional mixed-methods study protocol exploring the enablers and barriers for people with severe and enduring mental illness in Jamaica when accessing healthcare for chronic physical illness
} Patrice Whitehorne-Smith (D) , ${ }^{1}$ Sharyn Burns (D) , ${ }^{1}$ Ben Milbourn, ${ }^{2}$ Wendel Abel, ${ }^{3}$
Robyn Martin ${ }^{2}$

To cite: Whitehorne-Smith $\mathrm{P}$, Burns S, Milbourn B, et al. Cross-sectional mixed-methods study protocol exploring the enablers and barriers for people with severe and enduring mental illness in Jamaica when accessing healthcare for chronic physical illness. BMJ Open 2020;10:e038245. doi:10.1136/ bmjopen-2020-038245

- Prepublication history for this paper is available online. To view these files, please visit the journal online (http://dx.doi org/10.1136/bmjopen-2020038245).

Received 08 March 2020 Revised 19 June 2020 Accepted 25 June 2020

A) Check for updates

(C) Author(s) (or their employer(s)) 2020. Re-use permitted under CC BY-NC. No commercial re-use. See rights and permissions. Published by BMJ.

For numbered affiliations see end of article.

\section{Correspondence to}

Patrice Whitehorne-Smith; p.whitehor@postgrad.curtin. edu.au

\section{ABSTRACT}

Introduction Extant international research suggests that people with severe and enduring mental illness (PWSEMI) experience increased rates of chronic physical illness (CPI), reduced life expectancy and higher mortality than those in the general population. The high prevalence of CPI among PWSEMI is associated with a number of barriers that this population experiences when accessing physical healthcare. Although substantial research has been conducted in North America, Europe and Australia, there appears to be a paucity of research exploring CPI among PWSEMI in the Caribbean region, although this region has reported very high rates of non-communicable diseases within its populations. The current study will be situated in Jamaica and will explore the enablers and barriers to PWSEMI accessing healthcare for CPI.

Methods and analysis A convergent mixed-method design will explore the enablers and barriers to accessing healthcare for CPI among PWSEMI. This cross-sectional study will collect data from PWSEMI, caregivers and family members, community health aides, primary care physicians, psychiatrists and health policymakers.

Ethics and dissemination The study findings will provide baseline data describing the prevalence of CPI among PWSEMI in Jamaica and will identify enablers for, and barriers to, PWSEMI accessing CPI care. Findings will be disseminated widely in Jamaica and internationally to key stakeholders through publications and conferences. Institutional ethical approval was granted from Jamaica's Ministry of Health and Wellness Medico-legal Ethics Review Panel (\# 2019/49), the Curtin University Human Research and Ethics Committee (HRE 2020-0022) and the University of the West Indies FMS Ethics Committee (ECP 101, 19/20).

\section{INTRODUCTION}

Severe and enduring mental illnesses (SEMI) are recognised as mental, behavioural or emotional conditions that are chronic, intense and debilitating. ${ }^{1}$ Worldwide, there
Strengths and limitations of this study

- Mixed-methods research offers a depth and breadth of understanding suited to the topic and the scoping approach, particularly given the dearth of research on the topic in Jamaica.

- Data collection with six participant groups creates multiple opportunities for data triangulation, thereby increasing the validity and trustworthiness of the results.

- The study will be guided by a stakeholder reference group with members from non-governmental organisations representing PWSEMI and their families, physicians, psychiatrists and mental health researchers who will guide the implementation of the study and dissemination of results.

- Resource and time constraints have led to the exclusion of private health sector stakeholders, which means a comparison between public and private mental health system experiences is not possible in this study.

are different ways of categorising SEMI and the group of disorders that constitute SEMI. ${ }^{2}$ This study adheres to the listing of conditions specified as SEMI by the Royal Australian and New Zealand College of Psychiatrists (RANZCP) and the Department of Health Australia (DoHA). These include schizophrenia and other psychotic disorders, bipolar disorder and clinically significant depression, anxiety disorders and substance use disorders ${ }^{34}$ where they have been assessed as severe and enduring based on the Diagnostic and Statistical Manual $-5{ }^{5}$ by a qualified psychiatrist.

The individual, social and economic burden of SEMI is reported to be a major 
global issue. ${ }^{6}$ International research suggests that people with severe and enduring mental illness (PWSEMI) are more likely to report a poor quality of life, unsatisfactory family, social and financial support, unemployment, homelessness and poverty. ${ }^{6} 7$ Moreover, PWSEMI have a higher rate of mortality and a significantly shorter life expectancy ( 15 to 30 years) than their counterparts in the general population. ${ }^{8-11}$ These documented negative risks are closely linked to the presence of comorbid (co-occurring) chronic physical illnesses (CPIs) among PWSEMI, which accounts for an estimated $60 \%$ of mortalities worldwide among this population. ${ }^{12}$

\section{SEMI and CPIs}

CPIs refer to physiological conditions that impair functioning and are longstanding and debilitating. ${ }^{13}$ The most prominent non-communicable CPI of global concern include cardiovascular and respiratory diseases, diabetes mellitus and cancers. ${ }^{14}$ Research indicates high rates of co-occurring SEMI with CPI. ${ }^{2} 615-17$ This comorbidity ranges between $19 \%$ and $68 \%$ within lower-income and middle-income countries. ${ }^{12}$ Furthermore, PWSEMI are at greater risk of obesity, diabetes mellitus, heart disease, cancers, respiratory diseases and reproductive diseases when compared with the general population. ${ }^{12} 13$ Compared with the general population, PWSEMI are two to three times and two to six times more likely to die from cardiovascular disease and respiratory diseases, respectively. ${ }^{10} 18-20$

Negative physical health outcomes among PWSEMI are linked to a number of factors, including the adverse effects of psychotropic drugs, ${ }^{21}$ which can increase the risk of metabolic, endocrine cardiovascular, respiratory, gastrointestinal, haematological and musculoskeletal diseases and disorders. ${ }^{28}$ 21-23 Smoking, poor nutrition, physical inactivity and limited health-seeking behaviours also contribute to negative physical health outcomes for the population. ${ }^{823} 24$

Additionally, it has been suggested that poor health outcomes for PWSEMI are directly linked to neglectful responses from health systems. ${ }^{24}$ Issues reported include access to and utilisation of health services, as well as physical and mental healthcare practitioners' not undertaking regular screening, treatment and monitoring of physical health problems as physical health complaints are often considered to be related to the mental health status of the patient. $^{25-29}$

\section{Access to healthcare services for physical illnesses among PWSEMI}

Access to healthcare is defined in this study as 'the opportunity to identify healthcare needs, to seek healthcare services, to reach, to obtain or use healthcare services, and to actually have the need for services fulfilled'. ${ }^{30}$ Factors that enable PWSEMI to access healthcare for CPI include: recognition by the individual that there is a need for healthcare; practical family or social support networks that encourage help-seeking; financial means to access care; and previous positive healthcare experiences. ${ }^{31}$ In contrast, barriers to access are reported to include the severity of illness as well as the availability of social and financial support to assist people in obtaining care who may not have the means or ability to do so on their own. ${ }^{31-35}$

Furthermore, it has been noted that clinical practice can create barriers to access to healthcare. These barriers include not regularly assessing or monitoring physical health and poor continuity of care for physical illness; ${ }^{36-39}$ somatic descriptions rejected and categorised as symptoms of mental illness; ${ }^{36}$ stigma; ${ }^{33}{ }^{40-42}$ the time required to treat those with SEMI and CPI ${ }^{40}$ and staff lacking skills in the management of psychiatric symptoms. ${ }^{26}$ Other health system barriers include: lack of funding for SEMI and $\mathrm{CPI} ;{ }^{41}$ inadequate healthcare facilities, particularly in rural areas; ${ }^{12}$ and fragmentation and separation of general health and mental health services. ${ }^{36} 374041$ Although barriers to accessing healthcare for PWSEMI are varied, stigma repeats in the literature as a major underpinning barrier. ${ }^{43-49}$ These factors are reportedly more significant in middle-income and low-income countries ${ }^{24}$ such as those in the Caribbean region.

\section{SEMI and CPI in Jamaica}

The Caribbean has seen an upward trend in the prevalence of non-communicable diseases (NCDs) over the past decades with ischaemic heart disease, cardiovascular disease and diabetes mellitus reported as the most prevalent in the region. ${ }^{50}$ Given the increased risk for these CPI among PWSEMI, it is vital that this population's ability to access healthcare is better understood and is the impetus for this research.

Jamaica is a small island nation within the Caribbean region and will be the location of the study. Jamaica has been selected as the location of this research as it has a well-developed government-funded mental health service which largely follows a community mental healthcare mode $^{51}$ allowing for the accessibility of the study population. Furthermore, it is the home country of the lead author.

A detailed search of relevant databases (Google Scholar, ProQuest and PsycINFO) along with dialogue with four leading Jamaican public and mental health researchers revealed no known research examining access to care for CPI among PWSEMI in Jamaica or the wider Caribbean. This highlights a significant gap in research specific to PWSEMI in the region, especially given the "chronic disease epidemic' in the Caribbean ${ }^{50}$

The most recent data suggests that the prevalence of severe mental disorders ranges from $2.0 \%$ to $10.0 \%$ in Latin America and the Caribbean. ${ }^{52}$ In Jamaica, there is a lack of representative population-based data on the prevalence of SEMI. ${ }^{53}$ Data from government mental health community-based services reveals that the most common primary diagnoses are schizophrenia $(51 \%), \operatorname{mood}$ and affective disorders $(36 \%)$ and substance use disorders (4\%). ${ }^{54}$ 


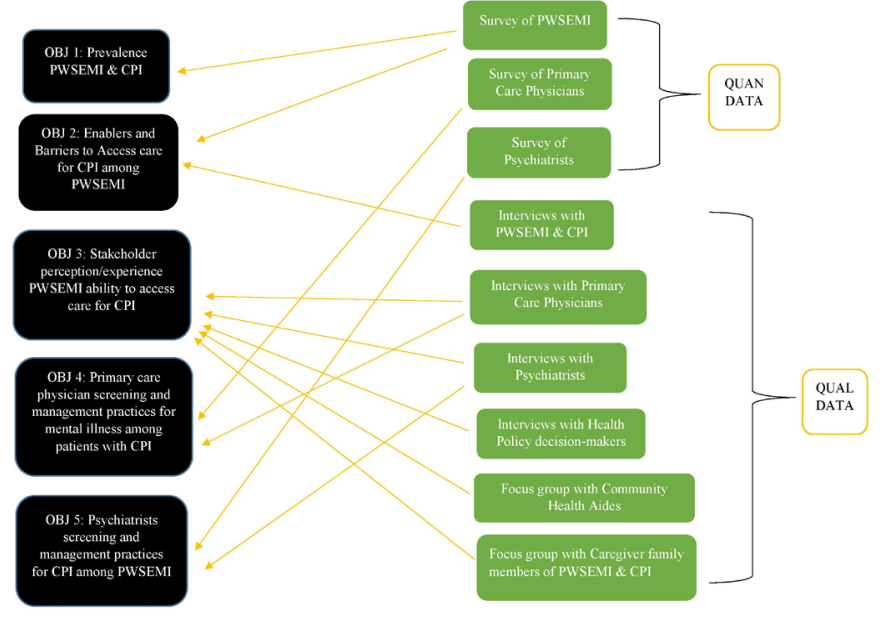

Figure 1 Research objectives link to data collection method. CPI, chronic physical illness; PWSEMI, people with severe and enduring mental illness.

Jamaica has made efforts towards integrating mental healthcare into primary physical health care, ${ }^{55}$ with primary care physicians expected by the public health system to screen and manage patients with SEMI. ${ }^{51}{ }^{56}$ However, a recent study identified that few primary care physicians (16.7\%) screen for depression, with the majority $(66.7 \%)$ reporting they felt ill-equipped to manage depression despite demonstrating adequate knowledge. ${ }^{57}$ The findings from this study suggest that primary physicians may have sufficient knowledge to assess for mental health conditions, but lack the capacity to undertake the ongoing management of this group. This is noteworthy as an earlier study conducted among CPI inpatients revealed that $60.5 \%$ experienced depressive symptoms ${ }^{58}$ and it is unclear what percentage received treatment for these symptoms.

\section{METHODS AND ANALYSIS}

\section{Aims and objectives}

The study aims to identify enablers and barriers experienced by PWSEMI when accessing healthcare for CPIs in Jamaica.

The objectives of the study are:

1. To determine the prevalence of CPI among PWSEMI attending community mental health clinics in Jamaica.

2. To identify enablers and barriers to accessing healthcare services for CPI among PWSEMI.

3 . To consider and evaluate the perceptions and experiences of stakeholders regarding PWSEMI and their ability to access healthcare services for CPIs.

4. To investigate attitudes, and health screening and management practices of primary care physicians for PWSEMI who have CPIs.

5. To investigate attitudes, and health screening and management practices of psychiatrists for PWSEMI who have CPIs.

\section{Study design}

A convergent mixed-methods approach will be used to collect, analyse and interpret the data. ${ }^{59}$ The approach reflects the multifaceted nature of the aims and objectives. ${ }^{60}$ The quantitative strand will promote the generalisability of results related to the prevalence and scope of the issue of CPI among PWSEMI, and the practices of physicians and psychiatrists. However, the qualitative strand will be dominant as it will allow for rich and thick descriptions of people's experiences. The social constructivist grounded theory methodology will guide the qualitative strand. ${ }^{61}$ Grounded theory is particularly useful to this study as it allows for an exploration of meaning and experience as a dynamic that plays out within and across individuals and groups. ${ }^{62}$

Quantitative and qualitative data will be collected simultaneously. ${ }^{59}$ The use of quantitative and qualitative strands will facilitate a holistic understanding of the phenomena under study and promote triangulation of the data. ${ }^{59}$ Questionnaires will be used to gather data related to objectives 1, 2, 4 and 5. Perceptions and experiences of enablers and barriers to accessing healthcare for PWSEMI (Objectives 2 to 5) will be explored using interviews and focus groups (figure 1).

\section{Setting}

This is a supervised doctoral research project for the lead author who has worked for over a decade as a psychologist and in mental health-related research in the Jamaican and Caribbean context. The study will take place at various sites across Jamaica and will involve a collaboration between Curtin University in Western Australia (the student's enrolling institution) and the University of the West Indies, Jamaica. Official permission will be sought from the Ministry of Health and Wellness, Jamaica, to collect survey data across selected community health centres and health department offices. The qualitative aspects of the study will be facilitated in spaces provided by the University of the West Indies, or in other private spaces deemed most convenient to study participants. The research data collection team will include the lead researcher and two research assistants from the University of the West Indies.

The study participants will be chosen based on their involvement and roles in the health system and their experiences as end-users. The participant groups will include: (a) PWSEMI; (b) family member caregivers of PWSEMI; (c) Ministry of Health and Wellness policy and decisionmakers; (d) primary care physicians; (e) psychiatrists; and (f) community health aides (CHAs). Participants will be recruited using various sampling strategies.

\section{Quantitative strand (objectives 1, 2, 4 and 5)}

\section{Sampling and data collection}

1. PWSEMI: Cluster sampling will be used to recruit a representative sample of 380 participants from a subset of 114 mental health clinics in Jamaica. Clinics will be divided into 14 region clusters. Simple random 
sampling will be used to select clinics from each cluster. The sample size was calculated based on a $95 \%$ CI and a $5 \%$ margin of error for the annual national clinic attendees' population of $30279 .^{5463}$

At selected clinics, the study will be introduced by the research team lead to prospective participants in the clinic waiting area. To be eligible for participation in the study, participants will have be 18 years or older, have a previously diagnosed SEMI, have not reported a psychiatric crisis for the past 7 days and consent to participate. Those who meet the criteria and express interest will be asked if they are willing to participate. On agreement, the participant information sheet will be explained and informed consent obtained. The questionnaire will be read and administered to ensure consistency and mitigate against issues of varying levels of literacy. Questions will be presented in Jamaica Standard English and then in Jamaican Patios if participants demonstrate difficulty understanding the questions. The questionnaire will take approximately 10 min to complete and will explore self-reported CPI, non-identifying demographics, length of diagnosis, and current experiences with screening and treatment for CPI.

2. Primary care physicians: Cluster sampling will be used to recruit a representative sample of 264 primary care physicians who attend monthly physician meetings in each of the 14 region clusters. Simple random sampling will be used to select meetings from which participants will be recruited. The sample size was calculated based on a $95 \%$ CI and a $5 \%$ margin of error for the population of primary care physicians of $841 .{ }^{6364}$ The inclusion criteria will be physicians currently working in public primary healthcare for a year or more. Primary care physicians not currently working in public service will be excluded from the study.

At the selected meetings, a research team member will introduce the study and participant information sheets, and consent forms will be distributed to physicians who indicate interest. Participants will be invited to complete a short 10 min questionnaire exploring attitudes towards mental illness, screening and management practices for CPI among patients with SEMI as well as for mental illness among patients with CPI. Training background along with perceived enablers and barriers to adequate screening and management practices will be explored. Additionally, participants will be asked if they are interested in participating in a qualitative interview.

3. Psychiatrists: An estimated 26 psychiatrists are employed in Jamaican public mental health services, ${ }^{54}$ hence the aim is to recruit all psychiatrists. Recruitment will occur at monthly mental health team meetings held at regional health authority offices. The inclusion criteria will be psychiatrists currently working in the public sector for a year or more. Psychiatrists not currently working in public service will be excluded from the study.
At the selected meetings, a research team member will introduce the study, and participant information sheets and consent forms will be distributed to physicians who indicate interest. Participants will be invited to complete a short 10 min questionnaire exploring attitudes towards CPI screening and management practices as well as attitudes and beliefs around mental illness and CPI. Training background along with perceived enablers and barriers to adequate screening and management practices will be explored. Additionally, participants will be asked if they are interested in participating in a qualitative interview.

\section{Qualitative strand (objectives 2 to 5)}

\section{Sampling and data collection}

This strand involves all the six participant groups. Participants will be recruited via purposive and snowball sampling techniques. All participants will be aged 18 years or over, and must be able to communicate in English or Jamaican Patois. Those who meet the criteria and express interest will be provided the participant information sheet and written consent will be obtained. Potential participants will have the option to ask questions about the research prior to providing consent. Interview questions will be presented in Jamaica Standard English or Jamaican Patios as deemed appropriate by the interviewer based on the participants' comfort level with each language. All aspects of the qualitative strand will be conducted by the lead author.

- PWSEMI: Up to 20 PWSEMI will be recruited. Participants must have a diagnosis of SEMI, self-report CPI and have not had a psychiatric crisis for 7 days prior to the interview. PWSEMI will be recruited via: (1) expression of interest when survey data was collected; (2) email response to flyers distributed by two nongovernmental mental health support groups; or (3) snowball sampling from existing participants who share the study flyer.

- Caregiver family members of PWSEMI: Up to 10 participants who self-identify as the primary person who provides physical, emotional and/or financial support for a PWSEMI will be recruited. ${ }^{65}$ Caregiver family members will be recruited via: (1) those present at the clinic at the time of the PWSEMI quantitative data collection will be asked about their interest in participating in this strand; (2) flyers distributed by email by two non-governmental mental health support groups; or (3) snowball sampling methods from existing participants who share the study flyer.

- Health policy decision-makers: Up to five Ministry of Health and Wellness policy decision-makers will be recruited. Participants will be current directors or appointed representatives in the Ministry with responsibility for health policy related to mental health, substance abuse and NCDs. There are no more than five persons who fit this profile within the Ministry. Participants will be recruited via an email invitation. 
- Primary care physicians: Up to 10 physicians, qualified for at least 1 year and who currently practice in primary public healthcare will be recruited via: (1) expression of interest when survey data was collected; (2) flyers emailed by the national medical associations and other medical networks; or (3) snowball sampling methods from existing participants who share the study flyer.

- Psychiatrists: Up to 10 psychiatrists, credentialed for at least 1 year and who are currently practicing psychiatry in the public system will be recruited via: (1) expression of interest when survey data was collected; (2) flyers emailed by the national medical associations and other medical networks, or (3) snowball sampling methods from existing participants who share the study flyer.

- CHAs: Up to 10 CHAs from 10 different communities across the four health regions will be recruited. These health workers represent the health system in the local community and have practical knowledge of the health concerns and issues facing community members. ${ }^{55} \mathrm{~A}$ listing of CHAs and their contact information will be obtained from the Regional Health Authorities. There are an estimated 3 to 4 CHAs in communities where there are health clinics. ${ }^{54}$ CHAs who have been in their role for at least a year and who are from community clinics included in the PWSEMI cluster sampling will be contacted via telephone and/or email and recruited for participation in the study.

\section{Semi-structured interviews}

Four participant groups: PWSEMI, health policy decisionmakers, and primary care physicians and psychiatrists will participate in semi-structured individual face-to-face interviews of up to 60 min duration. Semi-structured interviews as a data collection tool will allow for a detailed and intentional exploration of the experiences of these participants and provide a confidential space to share views, feelings and experiences. ${ }^{66}$ Interviews will be conducted at a time and place convenient to the participants and semi-structured interview guides will direct participant interviews. ${ }^{66-68}$

The PWSEMI interview guide will explore perceptions and experience of accessing healthcare services for their CPI and enablers and barriers to accessing health services. The health policy decision-maker interviews will explore perceptions and experiences related to addressing mental illness and comorbid SEMI and CPI, public health responses to SEMI and CPI as well as enablers and barriers to service delivery.

The interview guides for primary care physicians and psychiatrists will explore perspectives, attitudes and practices in relation to screening, management and referral of PWSEMI for physical healthcare, management of comorbidity and their perceptions of the enablers and barriers to care for CPI among PWSEMI.

\section{Focus group discussions}

Focus group discussions (FGD) will be conducted with approximately 10 CHAs and 10 caregiver family member groups (one FGD, respectively). An FGD approach was chosen to promote sharing of experience as a way to facilitate rich and thick descriptions. Furthermore, such a setting may offer a measure of social support to participants. ${ }^{66}$ Each FGD is expected to take approximately $90 \mathrm{~min}$. The CHA focus group will explore perspectives about and experiences with PWSEMI in the community setting and access, and enablers and barriers in relation to healthcare services for PWSEMI and CPI. The caregiver family focus group will explore experiences of navigating health services, particularly around accessing healthcare for CPI for their family member with a SEMI. The discussion will also explore their perceptions of enablers and barriers to accessing these services.

\section{Patient and public involvement}

Six persons who fall within the study target population or who are representatives of the interests of study participant groups will be involved in the design of the study instrument, implementation and dissemination of study findings through their participation in a stakeholder reference group. The group will include three members from mental health support and advocacy groups who will represent the interest of PWSEMI and their caregiver family members, a primary care physician, psychiatrist and mental health researcher. These individuals will not participate in the study outside of being a member of this group. The group will be asked to provide consultation around four key areas of the project: (1) strategies for sensitising relevant stakeholders including potential participants about the study; (2) the appropriateness and adequacy of data collection instruments and implementation plan; (3) mid-point review of the data collection process to discuss successes, challenges and brainstorm strategies for addressing any emerging concerns; and (4) at completion of data collection, to discuss study findings, and appropriate dissemination strategies to facilitate impact and stakeholder action. The inclusion of this kind of consultation throughout the research process will likely enhance the research accountability as well as the overall quality and validity of the study.

\section{Data analysis}

Data from the quantitative and qualitative strands will be analysed separately and then synthesised and interpreted. ${ }^{59}$ Quantitative data will be inputted into three different databases using the Statistical Package for the Social Sciences (SPSS) V.25. ${ }^{69}$ The data from each group of participants will then be cleaned, and descriptive and inferential statistical operations performed separately on each database in keeping with the study objectives. ${ }^{70}$

Qualitative data will be analysed using constructivist grounded theory techniques such as constant case comparison between and across data sources, negative case analysis (only as emergent in the data) and 


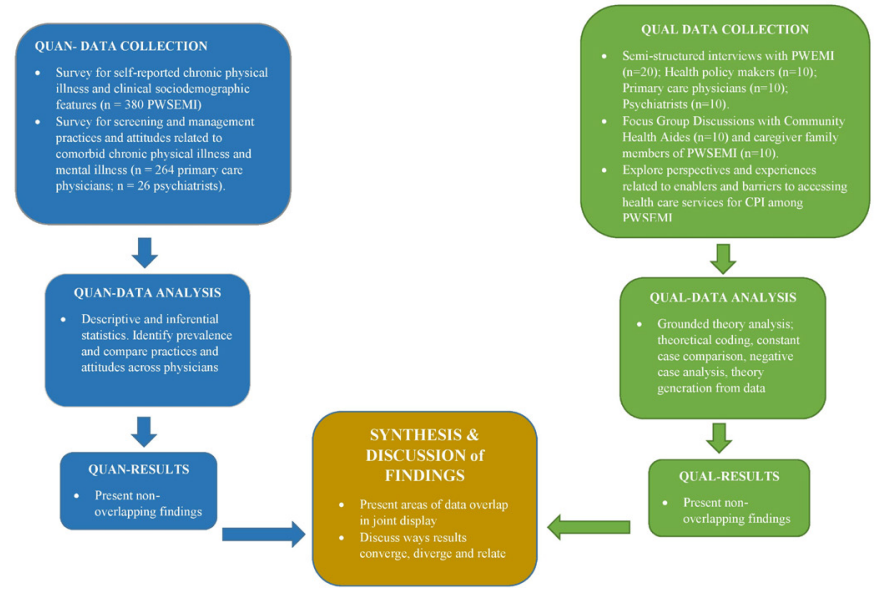

Figure 2 Diagram of proposed study design and data analysis plan in keeping with 59 convergent mixed-methods approach. CPI, chronic physical illness; PWSEMI, people with severe and enduring mental illness.

generation of codes and categories; initial, focussed codes and theoretical categories. ${ }^{61} 7172$ The NVivo V.12 software will be used to assist with the creation of coding systems. ${ }^{73}$ This process will allow the researcher to identify links and relationships between the enablers and barriers to accessing healthcare services for the service user target group. Then, the synthesising of the quantitative and qualitative strands will involve primary data analysis and integration procedures. ${ }^{59}$ Areas of similarity in both strands of data, such as questions related to enablers and barriers will be identified and joint display tables or graphs will be presented where results are confirming ${ }^{59}$ (figure 2). Where results are disconfirming, further analysis will be undertaken to try to understand and explain the divergence. ${ }^{74}$

\section{Rigour}

A number of strategies to ensure the rigour of this research will be used such as reflexivity. The reflexivity of the research will include critical reflection with the research and supervisory teams in order to examine and address areas of potential bias. ${ }^{66}$ Bracketing will be used to discuss and record any researcher bias by the lead researcher at the start of the research project. ${ }^{61}$ Memo writing will report justifications for any changes in direction related to methods, analysis or presentation of findings. ${ }^{66}$ Credibility will be enhanced by member checking, which will involve participant review of their interview transcripts. ${ }^{75}$ Participants will be given 2 weeks following their interview to respond with any changes. Direct, non-identifiable quotations from participants will be used to express central ideas emergent from the data to support interpretations. ${ }^{75}$ Finally, this study will involve data source triangulation as data will be collected and compared from six different groups of participants which will contribute to the rigour, trustworthiness and validity of the study. ${ }^{66} 76$

\section{ETHICS AND DISSEMINATION}

This study has received institutional ethical approval from Jamaica's Ministry of Health and Wellness Medico-legal Ethics Committee (\# 2019/49) and Curtin University Human Research Ethics Committee (HRE 2020-0022).

Prior to providing any data, prospective participants will be provided with participant information sheets and the study will be explained. Written consent will be obtained from all participants. ${ }^{77}$ The participant information sheets will include a study overview and an outline that participation is voluntary and without repercussions for withdrawal. ${ }^{77}$ PWSEMI, caregivers and the CHAs will be recognised for their contributions in the form of a mobile telephone top-up voucher valued at $\$ 500$ JMD.

In order to facilitate anonymity, no personal identifiers will be collected for the quantitative strand of the study. Whereas, for the qualitative strand, pseudonyms will be assigned to each participant and used on transcripts and reporting documents. Given the potentially sensitive nature of the topics covered in interviews and focus groups, participant information sheets will include contact details for a free counselling service in the advent that participants experience distress due to participating in this study. ${ }^{77}$

As knowledge transfer is an important consideration for this research project, the findings of this study will be disseminated in several ways. ${ }^{78}$ This research project is a doctoral thesis, with findings published in academic journals and submitted to a dissertation repository as well as presented at academic conferences. Additionally, key findings will be shared in the form of a report to the Ministry of Health and Wellness and engagement through presentations and information sheets to consumer groups as guided by the stakeholder reference group.

\section{Author affiliations}

${ }^{1}$ School of Public Health, Curtin University, Perth, Western Australia, Australia

${ }^{2}$ School of Occupational Health, Social Work and Speech Pathology, Curtin University Faculty of Health Sciences, Perth, Western Australia, Australia

${ }^{3}$ Community Health \& Psychiatry, University of the West Indies, Kingston, Kingston, Jamaica

Acknowledgements The authors acknowledge Dr Daniel Oshi of the University of the West Indies for his support and assistance with the study. We also wish to thank those who have committed to be a part of the stakeholder reference group for the study.

Contributors All authors contributed significantly to the conceptualisation, design and drafting of this paper. PW-S conceived the study which was expanded and refined through consultation and guidance from RM, WA, BM and SB who helped to solidify the direction of the study. PW-S drafted the paper and SB, BM, WA and RM critically reviewed and edited the paper. All authors approved the final manuscript.

Funding This research project is funded through the Australian Government Research Training Program Stipend Scholarship and administered through the doctoral programme run at Curtin University's School of Public Health.

Disclaimer The views expressed in this submitted work are those of the authors and do not represent those held by Curtin University or the University of the West Indies.

Competing interests None declared.

Patient consent for publication Not required.

Provenance and peer review Not commissioned; externally peer reviewed. 
Open access This is an open access article distributed in accordance with the Creative Commons Attribution Non Commercial (CC BY-NC 4.0) license, which permits others to distribute, remix, adapt, build upon this work non-commercially, and license their derivative works on different terms, provided the original work is properly cited, appropriate credit is given, any changes made indicated, and the use is non-commercial. See: http://creativecommons.org/licenses/by-nc/4.0/.

\section{ORCID iDs}

Patrice Whitehorne-Smith http://orcid.org/0000-0001-5102-0261

Sharyn Burns http://orcid.org/0000-0002-1551-2805

\section{REFERENCES}

1 National Institute of Mental Health. Mental illness, 2019. Available: https://www.nimh.nih.gov/health/statistics/mental-illness.shtm

2 Freeth R. Political and philosophical dimensions of severe and enduring mental illness. In: Russello A, ed. Severe mental illness in primary care: a companion guide for counsellors, pychotherapists and other professionals. Abington. UK: Radcliffe publishing, 2007: 84-6.

3 Royal Australian and New Zealand College of Psychiatrists (RANZCP). The economic cost of serious mental illness and comorbidities in Australia and New Zealand. Victoria Institute of strategic economic studies, 2016. Available: https://www.ranzcp.org/ files/publications/ranzcp-serious-mental-illness.aspx

4 Department of Health-Australia (DoHA). National mental health report 2013: tracking progress of mental health reform in Australia 1993 - 2011, 2013. Available: https://www.health.gov.au/internet/main/ publishing.nsf/content/B090F03865A7FAB9CA257C1B0079E198/\% 24File/rep13.pdf

5 American Psychiatric Association. Diagnostic and statistical manual of mental disorders. 5 edn, 2013. https://journals.plos.org/plosone/ article?id=10.1371/journal.pone.0091936\#s1

6 World Health Organization. Risks to mental health: an overview of vulnerabilities and risk factors, 2012. Available: https://www.who. int/mental_health/mhgap/risks_to_mental_health_EN_27_08_12.pdf [Accessed 10 May 2019].

7 Druss BG. Mental disorders and medical comorbidity, 2011. Available: https://www.integration.samhsa.gov/workforce/mental disorders_and_medical_comorbidity.pdf [Accessed 10 May 2019].

8 Holt RIG, Peveler RC. Diabetes and cardiovascular risk in severe mental illness: a missed opportunity and challenge for the future. Pract Diab Int 2010;27:79-84.

9 Tidemalm D, Waern M, Stefansson C-G, et al. Excess mortality in persons with severe mental disorder in Sweden: a cohort study of 12 103 individuals with and without contact with psychiatric services. Clin Pract Epidemiol Ment Health 2008;4:23.

10 Laursen TM, Mortensen PB, MacCabe JH, et al. Cardiovascular drug use and mortality in patients with schizophrenia or bipolar disorder: a Danish population-based study. Psychol Med 2014;44:1625-37.

11 Harris EC, Barraclough B. Excess mortality of mental disorder. Br J Psychiatry 1998;173:11-53.

12 DE Hert M, Correll CU, Bobes J, et al. Physical illness in patients with severe mental disorders. I. prevalence, impact of medications and disparities in health care. World Psychiatry 2011a;10:52-77.

13 Center for Disease Control. Mental health \& chronic diseases, 2012. Available: https://www.cdc.gov/workplacehealthpromotion/toolsresources/pdfs/issue-brief-no-2-mental-health-and-chronic-disease. pdf [Accessed 12 May 2019].

14 Institute for Health Metrics and Evaluation (IHME). Findings from the global burden of disease study 2017. Seattle, WA, 2018

15 Australia Institute of Health and Welfare. Mental health services in Australia, 2019. Available: https://www.aihw.gov.au/reports/mentalhealth-services/mental-health-services-in-australia/report-contents/ summary/prevalence-and-policies\#references [Accessed 12 May 2019].

16 Morgan VA, Waterreus A, Jablensky A, et al. People living with psychotic illness in 2010: the second Australian national survey of psychosis. Aust N Z J Psychiatry 2012;46:735-52.

17 Prince M, Patel V, Saxena S, et al. No health without mental health. Lancet 2007;370:859-77.

18 Nordentoft M, Wahlbeck K, Hällgren J, et al. Excess mortality, causes of death and life expectancy in 270,770 patients with recent onset of mental disorders in Denmark, Finland and Sweden. PLoS One 2013;8:e55176.

19 Crump C, Sundquist K, Winkleby MA, et al. Comorbidities and mortality in bipolar disorder: a Swedish national cohort study. JAMA Psychiatry 2013;70:931-9.
20 Crump C, Winkleby MA, Sundquist K, et al. Comorbidities and mortality in persons with schizophrenia: a Swedish national cohort study. Am J Psychiatry 2013;170:324-33.

21 Correll CU, Detraux J, De Lepeleire J, et al. Effects of antipsychotics, antidepressants and mood stabilizers on risk for physical diseases in people with schizophrenia, depression and bipolar disorder. World Psychiatry 2015;14:119-36.

22 Filaković P, Petek Erić A, Radanović-Grgurić L. Metabolic syndrome and psychotropic medications. Med Glas 2012;9:180-8.

23 Robson D, Haddad M. Mental health nurses' attitudes towards the physical health care of people with severe and enduring mental illness: the development of a measurement tool. Int J Nurs Stud 2012;49:72-83.

24 De Hert M, Cohen D, Bobes J, et al. Physical illness in patients with severe mental disorders. II. barriers to care, monitoring and treatment guidelines, plus recommendations at the system and individual level. World Psychiatry 2011b;10:138-51.

25 Maj M. Physical health care in persons with severe mental illness: a public health and ethical priority. World Psychiatry 2009;8:1-2.

26 Fagiolini A, Goracci A. The effects of undertreated chronic medical illnesses in patients with severe mental disorders. J Clin Psychiatry 2009;70:22-9.

27 Mitchell AJ, Malone D, Doebbeling CC. Quality of medical care for people with and without comorbid mental illness and substance misuse: systematic review of comparative studies. Br J Psychiatry 2009;194:491-9.

28 Kisely S, Smith M, Lawrence D, et al. Inequitable access for mentally ill patients to some medically necessary procedures. CMAJ 2007;176:779-84.

29 Parks J, Svendsen D, Singer P, et al. Morbidity and mortality in people with serious mental illness. Alexandria. National association of state mental health program directors (NASMHPD) medical directors Council, 2012. Available: https://www.nasmhpd.org/sites/ default/files/Reclaiming\%20Lost\%20Decades\%20Full\%20Report. pdf[Accessed 14 May 2019].

30 Levesque J-F, Harris MF, Russell G. Patient-Centred access to health care: conceptualising access at the interface of health systems and populations. Int J Equity Health 2013;12:9.

31 Nath SB, Wong Y-LI, Marcus SC, et al. Predictors of health services utilization among persons with psychiatric disabilities engaged in supported independent housing. Psychiatr Rehabil $J$ 2012;35:315-23.

32 Sokal J, Messias E, Dickerson FB, et al. Comorbidity of medical illnesses among adults with serious mental illness who are receiving community psychiatric services. J Nerv Ment Dis 2004;192:421-7.

33 Phelan M, Stradins L, Morrison S. Physical health of people with severe mental illness. BMJ 2001;322:443-4.

34 Goldman LS. Medical illness in patients with schizophrenia. J Clin Psychiatry 1999;60:10-15.

35 Jeste DV, Gladsjo JA, Lindamer LA, et al. Medical comorbidity in schizophrenia. Schizophr Bull 1996;22:413-30.

36 Lawrence D, Kisely S. Inequalities in healthcare provision for people with severe mental illness. J Psychopharmacol 2010;24:61-8.

37 Robson D, Gray R. Serious mental illness and physical health problems: a discussion paper. Int J Nurs Stud 2007;44:457-66.

38 Greening J. Physical health of patients in rehabilitation and recovery: a survey of case note records. Psychiatr Bull 2005;29:210-2.

39 Burns T, Cohen A. Item-of-service payments for general practitioner care of severely mentally ill persons: does the money matter? $\mathrm{Br} \mathrm{J}$ Gen Pract 1998;48:14-15.

40 Kane JM. Creating a health care team to manage chronic medical illnesses in patients with severe mental illness: the public policy perspective. J Clin Psychiatry 2009;70:37-42.

41 Fleischhacker WW, Cetkovich-Bakmas M, De Hert M, et al. Comorbid somatic illnesses in patients with severe mental disorders: clinical, policy, and research challenges. J Clin Psychiatry 2008;69:514-9.

42 World Health Organization (WHO). The mental health context. Available: https://www.who.int/mental_health/policy/services/3 context WEB 07.pdf

43 Cochrane LJ, Olson CA, Murray S, et al. Gaps between knowing and doing: understanding and assessing the barriers to optimal health care. J Contin Educ Health Prof 2007;27:94-102.

44 Dennis C-L, Chung-Lee L. Postpartum depression help-seeking barriers and maternal treatment preferences: a qualitative systematic review. Birth 2006;33:323-31.

45 Dixon-Woods M, Kirk D, Agarwal S. Vulnerable groups and access to health care: a critical interpretive review. report for the national coordinating centre for NHS service delivery and organisation R \& D (NCCSDO), 2005. Available: http://www.sdo.nihr.ac.uk/files/project/ SDO_ES_08-1210-025_V01.pdf [Accessed 14 May 2019]. 
46 Prins MA, Verhaak PFM, Bensing JM, et al. Health beliefs and perceived need for mental health care of anxiety and depression--the patients' perspective explored. Clin Psychol Rev 2008;28:1038-58.

47 Rodríguez M, Valentine JM, Son JB, et al. Intimate partner violence and barriers to mental health care for ethnically diverse populations of women. Trauma Violence Abuse 2009;10:358-74.

48 Scheppers E, van Dongen E, Dekker J, et al. Potential barriers to the use of health services among ethnic minorities: a review. Fam Pract 2006;23:325-48.

49 Van Voorhees BW, Walters AE, Prochaska M, et al. Reducing health disparities in depressive disorders outcomes between non-Hispanic whites and ethnic minorities: a call for pragmatic strategies over the life course. Med Care Res Rev 2007;64:157S-94S.

50 Pan American Health Organization. The Caribbean chronic disease epidemic: what we know... and what we need to know", 2017. Available: https://www.healthycaribbean.org/wp-content/uploads/ 2017/05/Hospedales_to_CHIRS_Oct_08_What_we_know_about NCDs_in_Caribbean.pdf [Accessed 16 May 2019].

51 Abel WD, Kestel D, Eldemire-Shearer D, et al. Mental health policy and service system development in the English-speaking Caribbean. West Indian Med J 2012;61:475-82.

52 Kohn R, Ali AA, Puac-Polanco V, et al. Mental health in the Americas: an overview of the treatment gap. Rev Panam Salud Publica 2018;42:1-10.

53 Hickling FW. The epidemiology of schizophrenia and other common mental health disorders in the English-speaking Caribbean. Rev Panam Salud Publica 2005;18:256-62.

54 Ministry of Health \&Wellness Jamaica. WHO-AIMS database on mental health systems in Jamaica. Kingston: Jamaica, 2015

55 Abel W, Sewell C, Thompson E, et al. Mental health services in Jamaica: from institution to community. Ethn Inequal Health Soc Care 2011;4:103-11.

56 Caldas de Almeida JM, Horvitz-Lennon M. Mental health care reforms in Latin America: an overview of mental health care reforms in Latin America and the Caribbean. Psychiatr Serv 2010;61:218-21.

57 Gibson RC, Walcott G. Are primary care physicians equipped to help persons with depression? an exploration of knowledge, attitudes and practices in Kingston, Jamaica. West Indian Med J 2016;189.

58 Morgan AN, Whitehorne-Smith P, Coore A, et al. The prevalence of depression among medical inpatients at the university hospital of the West Indies, Jamaica. WIMJ Open 2015;2:33-5.

59 Creswell JW, Plano Clark VL. Designing and conducting mixed methods research. 3 edn. Los Angeles, CA: Sage Publications, 2018.

60 Guetterman TC, Babchuk WA, Howell Smith MC, et al. Contemporary approaches to mixed methods-grounded theory research: a FieldBased analysis. J Mix Methods Res 2019;13:179-95.
61 Charmaz C. Constructing grounded theory: a practical guide through qualitative analysis. London: Sage, 2006.

62 McGowan MW, Turner LA. Grounded theory in practice: is it inherently mixed methods. Psychol Sch 2010;13:65-78.

63 Qualtrics. Sample size calculator. Available: https://www.qualtrics. $\mathrm{com} / \mathrm{blog} /$ calculating-sample-size/ [Accessed 12 May 2019].

64 Knight-Madden J, Gray R. The accuracy of the Jamaican national physician register: a study of the status of physicians registered and their countries of training. BMC Health Serv Res 2008;8:253.

65 Schulz R, Eden J. Families caring for an aging America. Washington (DC: National Academies Press (US), 2016.

66 Liamputtong P. Qualitative research methods. 4 edn. South Melbourne,Victoria: Oxford University Press Australia, 2013.

67 Turner DW. Qualitative interview design: a practical guide for novice Investigators. Qual Rep2010;15:754-60.

68 McNamara C. General guidelines for conducting interviews, 2009. Available: http://managementhelp.org/evaluatn/intrview.htm [Accessed 15 May 2019].

69 Corporation IBM. Statistical package for the social sciences version 25, 2017. Available: https://www-01.ibm.com/support/docview.wss? uid=swg27049975 [Accessed 15 May 2019].

70 Bryman A. Social research methods. 4 edn. Oxford: Oxford University Press, 2012.

71 Corbin J, Strauss A. Basics of qualitative research: techniques and procedures for developing grounded theory. 3 edn. Los Angeles: Sage, 2008.

72 Bryant A, Charmaz K. Handbook of grounded theory. London: Sage, 2007.

73 QSR International. N-Vivo 12, 2018. Available: https://www. qsrinternational.com/nvivo/enabling-research/the-new-nvivo [Accessed 15 May 2019].

74 Creswell JW. Designing and conducting mixed methods research. 2 edn. Los Angeles, CA: Sage Publications, 2011.

75 Carpenter CM, Suto M. Qualitative research for occupational and physical therapists: a practical guide. Wiley: Oxford, 2008.

76 Al-Busaidi ZQ. Qualitative research and its uses in health care. Sultan Qaboos Univ Med J 2008;8:11-19.

77 Australian Government. Australian code for the responsible conduct of research. Canberra: Australian Government, 2007. https://www. nhmrc.gov.au/sites/default/files/documents/attachments/grant\% 20documents/The-australian-code-for-the-responsible-conduct-ofresearch-2018.pdf

78 Canadian Institute of Health Research. KT knowledge base: KT clearing house, 2014. Available: https://ktclearinghouse.ca/ knowledgebase [Accessed 10 Dec 2019]. 